\title{
STUDI AWAL SENYAWA BENZO (A) PYRENE DALAM CONTOH UJI UDARA AMBIEN AKIBAT PEMBAKARAN BRIKET BATUBARA
}

Rita Mukhtar, Esrom Hamonangan, Erini Yuwatini, Bambang Hindratmo, Rina Aprishanty ${ }^{1}$

(Diterima tgl : 1-11-2010; Disetujui tgl : 16-12-2010)

\begin{abstract}
The used of coal briquette as an alternative energy fuels could generate negative impact on human health and environment, because it would raise the concentration of air pollution, such as the organic compound like benzo (a) pyrene. The aim of this research is to know the effect of combustion of coal briquette to ambien air quality due to emission of air pollutants. This research used experimental method. The combustion of coal briquette in this test used simulation technique. The sampling of ambient air quality was taken before and after combustion using standardized method High Volume Air Sampler (HVAS). The air sample was analyzed in laboratory according to using EPA-method TO-13 High Performance Liquid Chromatography (HPLC) equipment. The results of ambient air analyses average value Benzo (a) pyrene before and after combustion coal briquette is $\pm 0.0022 \mu \mathrm{g} / \mathrm{m} 3$ and \pm $0.01741 \mu \mathrm{g} / \mathrm{m} 3$ Analyzed using $t$ test with an alpha (a) of 0,05, there is significante concentration different before and after experiments were conducted.
\end{abstract}

Keywords: Coal Briquette, Benzo(a)pyrene, High Volume Air Sampler (HVAS), High Performance Liquid Chromatography (HPLC)

\begin{abstract}
ABSTRAK
Penggunaan briket batubara sebagai alternatif bahan bakar dapat menimbulkan akibat negatif terhadap kesehatan manusia dan lingkungan, karena dapat meningkatkan konsentrasi pencemaran udara misalnya senyawa organik seperti Benzo (a) pyrene. Penelitian ini bertujuan untuk mengetahui kualitas udara ambien akibat pembakaran briket batubara. Penelitian ini menggunakan metode eksperimen. Pembakaran briket batubara dilakukan dengan cara simulasi, contoh uji udara ambien diambil sebelum dan sesudah pembakaran dengan metode standar menggunakan alat High Volume Air Sampler (HVAS). Analisis contoh uji udara di laboratorium menggunakan metode EPA-TO-13 dengan menggunakan alat HPLC. Hasil penelitian menunjukkan nilai rata-rata Benzo(a)pyrene sebelum dan sesudah pembakaran briket batu bara berturut-turut adalah $0.0022 \mu \mathrm{g} / \mathrm{m} 3$ dan $0.01741 \mu \mathrm{g} / \mathrm{m} 3$. Berdasarkan uji-t dengan $\alpha$ $=0,05$ terdapat perbedaan nyata konsentrasi sebelum dan sesudah percobaan dilakukan.
\end{abstract}

Kata kunci: Briket batubara, Benzo (a) pyrene, High Volume Air Sampler (HVAS), High Performance Liquid Chromatography (HPLC)

\section{PENDAHULUAN}

Benzo(a)pyrene atau $\mathrm{BaP}$ adalah salah satu senyawa turunan Polycyclic Aromatic Hidrocarbons (PAH), yang memiliki lima (5) cincin benzene, rumus kimia $\mathrm{C} 20 \mathrm{H} 12$, berat molekul 252.32, dengan struktur molekul disajikan pada Gambar 1. BaP dijadikan sebagai indikator pencemaran $\mathrm{PAH}^{(1)}$. International Agency for Research on Cancer (IARC) menggolongkan BaP sebagai animal carcinogen dan probable human carcinogen (Group 2A). Pada binatang percobaan $\mathrm{BaP}$ telah terbukti sebagai agen kanker, mutasi gen, agen tumor, agen neoplastis dan teratogen. Pada manusia dapat menyebabkan kanker darah, kanker kulit, kanker paru, dapat merusak perkembangan janin dan kemungkinan menyebabkan kerusakan reproduktif ${ }^{(2)}$.

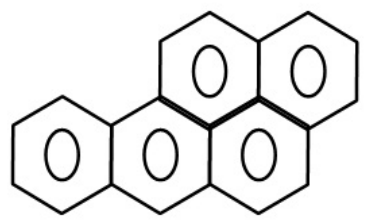

Gambar 1. Struktur Molekul Benzo(a)pyrene

\footnotetext{
${ }^{1}$ Pusat Sarana Pengendalian Dampak Lingkungan (PUSARPEDAL) Gedung 210 Kawasan Puspiptek Jl. Raya Puspiptek Serpong-

Tangerang BANTEN, T/F:021-7560983, Email: ritaiim@yahoo.com
} 
Keberadaan PAH di udara dapat disebabkan oleh dua hal yaitu secara alami dan kegiatan manusia atau antropogenik. Sumber PAH alami berasal dari kebakaran hutan, letusan gunung berapi, penguraian bahan organik oleh bakteri. PAH dari antropogenik dihasilkan dari pembakaran yang tidak sempurna, misalnya pembakaran bahan bakar fosil, seperti bensin dan solar pada mesin diesel, kegiatan yang menggunakan batubara seperti tungku briket batubara, proses gasifikasi batubara dan penghasil batubara, pembakaran sampah organik (insenerator), asap rokok, pabrik peleburan aluminium, besi dan baja, serta pada masakan yang dibakar (3). Pemajanan PAH di lingkungan dapat melalui emisi uap atau dalam bentuk ikatan pada debu partikulat di udara.

Penelitian emisi pembakaran batu bara pada suhu $600^{\circ} \mathrm{C}, 700^{\circ} \mathrm{C}, 800^{\circ} \mathrm{C}, 900^{\circ} \mathrm{C}, 1000^{\circ} \mathrm{C}$, $1100^{\circ} \mathrm{C}$, dan $1200^{\circ} \mathrm{C}$ di Cina menghasilkan senyawa BaP $1.598 \mu \mathrm{g} / \mathrm{g}, 1.855 \mu \mathrm{g} / \mathrm{g}, 21.668$ $\mu \mathrm{g} / \mathrm{g}, 0.763 \mu \mathrm{g} / \mathrm{g}, 4.002 \mu \mathrm{g} / \mathrm{g}, 8.631 \mu \mathrm{g} / \mathrm{g}$, $2.147 \mu \mathrm{g} / \mathrm{g}^{(3)}$.

Hasil penelitian $\mathrm{BaP}$ dalam partikulat udara di Niigata-Jepang pada tahun 1990 - 1993 di tiga (3) perkotaan berada pada kisaran 3.5$8.3 \mu \mathrm{g} / \mathrm{g} .{ }^{(1)}$.

Penelitian di Taiwan terdapat hubungan linear antara abu insinerator bekas pembakaran plastik PP, PVC dengan $\mathrm{PAH}^{(4)}$.

Baku mutu BaP diberbagai negara adalah sebagai berikut; di Italy batas konsentrasi $\mathrm{BaP}$ di udara ambien adalah $1 \mathrm{ng} / \mathrm{m} 3$. NIOS untuk IDLH (Imediete Dangerous Level for Health) adalah sebesar $80 \mathrm{mg} / \mathrm{m} 3$ (coal tar pitch volatiles benzo(a)pyrene). Menurut OSHA PEL dan ACGIH TLV adalah $0.2 \mathrm{mg}$ / m3 (coal tar pitch volatiles benzene soluble). Sedangkan menurut NIOSH REL adalah $0.1 \mathrm{mg} / \mathrm{m} 3$ (coal tar pitch volatiles benzo(a) pyrene) ${ }^{2)}$.

IPCS (1995) menyatakan Oral LD50 BaP sebesar $>1600 \mathrm{mg} / \mathrm{Kg}$ pada tikus. EPA menghitung risiko kanker oral dengan potensial faktornya adalah 7.3 (4.5-11.7) per $\mathrm{mg} / \mathrm{Kg} /$ hari $\mathrm{BaP}^{2}$.

Hasil penelitian tentang hubungan kualitas udara ambien, Indeks Standar Pencemar Udara (ISPU) dengan kejadian serangan Asthma/ bronkitis di DKI Jakarta pada tahun 20022003 menunjukkan tingginya angka pasien kanker paru-paru yang disebabkan karena pencemaran udara yang dihirupnya ${ }^{(5)}$.

Penelitian mengenai pencemaran udara akibat pembakaran briket batubara telah banyak dilaporkan oleh beberapa negara. Di Indonesia belum banyak penelitian PAH di lingkungan dan di dalam tubuh manusia (biomarker), sehingga Indonesia belum mempunyai standar baku mutu PAH di lingkungan.

Penelitian ini dilakukan untuk mendapatkan gambaran atau studi awal tentang Benzo(a) pyrene yang terdapat dalam contoh uji udara ambien yang dihasilkan dari pembakaran briket batubara.

Briket batubara merupakan bahan bakar padat yang terbuat dari batubara dengan sedikit campuran tanah liat dan tapioka. Briket batubara sebagai pengganti minyak tanah digunakan untuk pengolahan makanan, pengeringan, pembakaran dan pemanasan. Harga briket batubara relatif murah dan dimungkinkan untuk dikembangkan secara massal, teknologi dan peralatan yang digunakan relatif sederhana. Namun sebelumnya perlu 
ada kajian mengenai bahaya yang ditimbulkan akibat pembakaran briket batubara.

\section{METODOLOGI}

\section{Pengambilan Contoh Uji (Sampling)}

Penelitian ini menggunakan metode eksperimen. Contoh uji udara ambien diambil menggunakan alat High Volume Air Sampler (HVAS), dengan jenis filter glassfiber Whatman GF/A, panjang $25.5 \mathrm{~cm}$, lebar $20.5 \mathrm{~cm}$. Flowrate diatur 1,0-1,2 m3/ menit alat dijalankan selama 24 jam. Briket batubara dibakar dengan beberapa kompor yang sudah dirancang untuk pembakaran briket batubara, diantaranya kompor untuk penghangat kandang ayam, untuk kegiatan rumahtangga atau home industry, dan kompor untuk industri. Briket yang digunakan $16 \mathrm{Kg}$ untuk kompor ukuran besar dan $10 \mathrm{Kg}$ untuk industri kecil, $8 \mathrm{Kg}$ untuk kompor penghangat kandang ayam, 1-2 Kg untuk kompor rumah tangga. Kompor penghangat kandang ayam dinyalakan selama 8 jam, rumahtangga 2 jam, industri maksimal 4 jam. Perbedaan lama pembakaran berdasarkan asumsi lamanya kegiatan tersebut dilakukan. Sampling dilakukan sebelum proses pembakaran briket batubara dan pada saat proses pembakaran briket batubara pada jarak 20, 50, dan 60 meter dari tungku pembakaran briket batubara. Kondisi udara ambien diantaranya cuaca, temperatur, kelembaban udara, arah dan kecepatan angin diukur selama penelitian dilakukan.

\section{Proses Ekstraksi}

Filter hasil sampling diperlakukan dilaboratorium. Filter dipotong $1 \times 1 \mathrm{~cm}$ kemudian dimasukkan kedalam erlenmeyer bertutup, ditambahkan $50 \mathrm{~mL}$ dichloromethane, diultrasonik selama 20 menit. Hasil ekstrak di centrifuge pada $4000 \mathrm{rpm}$, selama 5 menit, ekstraksi diulangi dengan $50 \mathrm{~mL}$ dichloromethane lainnya, Hasil ekstrak dikumpulkan ke dalam labu jantung dan pelarut diuapkan hingga sampai $2 \mathrm{~mL}$ dengan rotary vacumn evaporator. Larutan dipindahkan ke dalam tabung uji $10 \mathrm{~mL}$ sambil dibilas dengan dichloromethane, volume dikurangi hingga 0,5 mL dengan gas N2 (6).

\section{Proses Clean Up}

Larutan hasil ekstraksi dilewatkan pada kolom $30 \times 1 \mathrm{~cm}$ yang mengandung 8 gr silica gel yang telah dipanaskan pada $130^{\circ} \mathrm{C}$ selama 24 jam dan diaktifkan kembali dengan 5\% air. Contoh uji dielusi dengan 25mL n-Hexane, kemudian dengan $40 \mathrm{~mL}$ n-Hexane-dichloromethane (4:1). Pelarut fraksi kedua ini diuapkan dengan rotary evaporator sampai larutan tinggal $5 \mathrm{~mL}$, sisanya dilarutkan dengan metanol, volume dijadikan sampai $10 \mathrm{~mL}$. Larutan siap diukur dengan alat HPLC (6).

Untuk mengetahui persentase keberhasilan metode dilakukan pengukuran recovery dengan penambahan standar (spike) pada contoh uji, kemudian dilakukan proses yang sama dengan contoh uji ektraksi dan clean up juga dilakukan untuk blanko dan spike.

\section{Pengukuran dengan HPLC}

Alat HPLC yang digunakan untuk analisis PAH adalah Merk Hitachi dengan pompa L-4200, Detektor yang digunakan adalah detektor Fruorescence dengan mengatur posisi panjang gelombang $\mathrm{BaP}$ tereksitasi 295nm dan emisi $405 \mathrm{~nm}$. Recorder Chromatogram D-2500, Kolom Varian ChromSpher PAH 4,6 $\mathrm{mm}$ id, panjang $150 \mathrm{~mm}$. Fase gerak : 
acetonitrile-air $(7: 3 \mathrm{v} / \mathrm{v})$, flowrate $3 \mathrm{~mL} / \mathrm{menit}$, volume injek $30 \mu \mathrm{L}$. Fase gerak dihomogenkan dan udara yang ada dalam larutan dikeluarkan dengan menggunakan ultrasonic pompa vacumn.

\section{Data Hasil Analisis}

Deret standar yang digunakan adalah $0,5,25$, 50, dan 100 ppb. Tinggi puncak dari grafik yang keluar sesuai dengan waktu retensi $\mathrm{BaP}$ merupakan konsentrasi BaP. Perhitungan konsentrasi BaP dengan membandingkan tinggi puncak grafik contoh uji dengan tinggi puncak standar yang di uji, melalui kurva kalibrasi.

\section{HASIL DAN PEMBAHASAN}

Pembuatan Kurva Kalibrasi:

Kurva kalibrasi BaP diperoleh dari tinggi puncak yang dihasilkan dari masingmasing standar yang diinjek, dengan 7 kali pengulangan. Tabel 1. menyajikan standar deviasi dan koefisien variasi kurva kalibrasi.

Tabel 1. Standar Deviasi (SD) dan Koefisien Variasi (CV) Kurva Kalibrasi

\begin{tabular}{|c|c|c|c|c|c|c|c|c|c|c|c|}
\hline $\begin{array}{c}\text { Konsentrasi } \\
(\mathrm{ppb})\end{array}$ & \multicolumn{7}{|c|}{ Tinggi Puncak (mm) } & \multirow{2}{*}{ rata2 } & SD & CV(\%) \\
\cline { 1 - 10 } Pengulangan & 1 & 2 & 3 & 4 & 5 & 6 & 7 & & & \\
\hline 0 & 0 & 0 & 0 & 0 & 0 & 0 & 0 & 7 & 0 & 0 & 0 \\
\hline 5 & 6 & 8 & - & 7 & - & 7 & 10 & 5 & 7,6 & 1,5 & 20,0 \\
\hline 25 & 22 & 25 & 27 & 38 & - & - & - & 4 & 28,0 & 7,0 & 24,9 \\
\hline 50 & 50 & 45 & 50 & 46 & 40 & 53 & 56 & 7 & 48,6 & 5,3 & 11,0 \\
\hline 100 & 107 & 113 & 108 & 123 & 105 & 100 & - & 6 & 109,3 & 7,9 & 7,2 \\
\hline
\end{tabular}

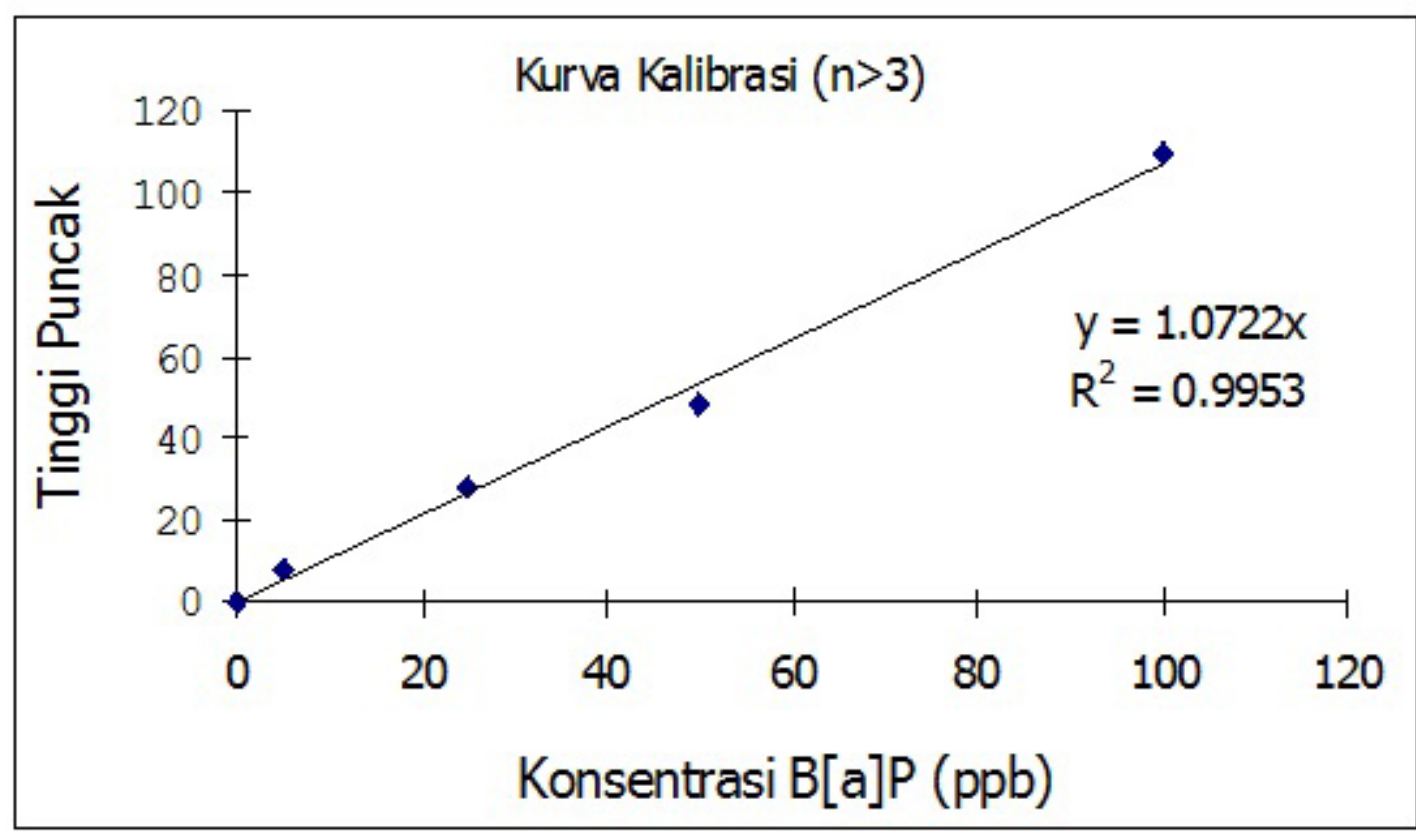

Gambar 2. Kurva Kalibrasi Benzo (a) pyrene 
Perhitungan Konsentrasi BaP

Dari persamaan garis lurus kurva kalibrasi pada Gambar 2., dapat dihitung konsentrasi $\mathrm{BaP}$ dalam contoh uji dengan rumus sebagai berikut:

$$
\mathrm{C}=\frac{(\mathrm{Ct}-\mathrm{Cb}) \times \mathrm{Vt} \times \mathrm{S} / \mathrm{St}}{\mathrm{V}}
$$

Keterangan:

$\mathrm{C}=$ Konsentrasi BaP di udara ambien $(\mu \mathrm{g} /$ m3)
$\mathrm{Ct}=$ Konsentrasi BaP dalam larutan uji $(\mu \mathrm{g} /$ $\mathrm{mL}$ )

$\mathrm{Cb}=$ Konsentrasi BaP dalam larutan blanko $(\mu \mathrm{g} / \mathrm{mL})$

$\mathrm{Vt}=$ Volume larutan uji $(\mathrm{mL})$

$\mathrm{S}=$ Luas contoh pada permukaan filter $(\mathrm{cm})$

$\mathrm{St}=$ Luas contoh yang di uji $(\mathrm{cm})$

$\mathrm{V}=$ Volume udara yang dihisap pada kondisi $25^{\circ} \mathrm{C}, 1 \mathrm{~atm}(\mathrm{~m} 3)$

\section{Konsentrasi BaP Sebelum Dan Sesudah}

\section{Pembakaran Briket Batubara}

Konsentrasi BaP didalam contoh uji disajikan pada Tabel 2

Tabel 2. Konsentrasi BaP Sebelum dan Sesudah Pembakaran Briket Batubara

\begin{tabular}{|c|c|c|c|c|c|c|c|}
\hline $\begin{array}{l}\text { Pembakaran } \\
\text { Briket } \\
\text { Batubara }\end{array}$ & $\begin{array}{l}\text { Kode } \\
\text { Contoh } \\
\text { uji }\end{array}$ & $\begin{array}{l}\text { Konsentrasi } \\
\text { BaP dalam } \\
\text { larutan uji } \\
\text { setelah } \\
\text { dikurangi } \\
\text { Blanko } \\
(\mathrm{Ct}-\mathrm{Cb}) \\
\quad(\mu \mathrm{g} / \mathrm{mL}) \\
\end{array}$ & $\begin{array}{l}\text { Volume } \\
\text { Udara } \\
\text { pada } \\
25^{\circ} \mathrm{C} \text {, } \\
1 \mathrm{~atm} . \\
(\mathrm{V}) \\
\left(\mathrm{m}^{3}\right) \\
\end{array}$ & $\begin{array}{l}\text { Luas } \\
\text { contoh } \\
\text { pada } \\
\text { permukaan } \\
\text { filter } \\
\text { (S) } \\
\quad \text { (cm) } \\
\end{array}$ & \begin{tabular}{l} 
Luas \\
contoh \\
filter \\
yang \\
diuji \\
(St) \\
\multicolumn{1}{c}{$(\mathrm{cm})$} \\
\end{tabular} & $\begin{array}{l}\text { Konsentrasi } \\
\mathrm{BaP} \\
\text { (C) }\end{array}$ & $\begin{array}{l}\text { Konsentrasi } \\
\text { BaP rerata }\end{array}$ \\
\hline \multirow{9}{*}{ Sebelum } & 1 & 0.0933 & 1619.4 & 522.75 & 129.54 & 0.00232 & \multirow{9}{*}{0.00222} \\
\hline & 2 & 0.0933 & 1727.9 & 522.75 & 129.54 & 0.00218 & \\
\hline & 3 & 0.0933 & 1743.0 & 522.75 & 129.54 & 0.00216 & \\
\hline & 4 & 0.0933 & 1619.4 & 522.75 & 129.54 & 0.00232 & \\
\hline & 5 & 0.0933 & 1727.9 & 522.75 & 129.54 & 0.00218 & \\
\hline & 6 & 0.0933 & 1743.0 & 522.75 & 129.54 & 0.00216 & \\
\hline & 7 & 0.0933 & 1619.4 & 522.75 & 129.54 & 0.00232 & \\
\hline & 8 & 0.0933 & 1727.9 & 522.75 & 129.54 & 0.00218 & \\
\hline & 9 & 0.0933 & 1743.0 & 522.75 & 129.54 & 0.00216 & \\
\hline \multirow{9}{*}{ Sesudah } & $1 \mathrm{~A}$ & 0.8394 & 1619.4 & 522.75 & 129.54 & 0.02092 & \multirow{9}{*}{0.01741} \\
\hline & $2 \mathrm{~A}$ & 0.1866 & 1638.7 & 522.75 & 129.54 & 0.00459 & \\
\hline & $3 \mathrm{~A}$ & 0.9327 & 1638.7 & 522.75 & 129.54 & 0.02296 & \\
\hline & $4 \mathrm{~A}$ & 0.2798 & 1727.9 & 522.75 & 129.54 & 0.00653 & \\
\hline & $5 \mathrm{~A}$ & 1.2125 & 1727.9 & 522.75 & 129.54 & 0.02831 & \\
\hline & $6 \mathrm{~A}$ & 0.7461 & 1727.9 & 522.75 & 129.54 & 0.01742 & \\
\hline & $7 \mathrm{~A}$ & 0.6529 & 1746.3 & 522.75 & 129.54 & 0.01508 & \\
\hline & $8 \mathrm{~A}$ & 0.8394 & 1747.7 & 522.75 & 129.54 & 0.01938 & \\
\hline & $9 \mathrm{~A}$ & 0.9327 & 1750.3 & 522.75 & 129.54 & 0.02150 & \\
\hline
\end{tabular}


Hasil analisis BaP menunjukkan adanya perbedaan nyata rata-rata konsentrasi $\mathrm{BaP}$ sebelum pembakaran briket batubara yaitu $0.0022 \mu \mathrm{g} / \mathrm{m} 3$ dengan konsentrasi rata-rata $\mathrm{BaP}$ sesudah pembakaran briket batubara yaitu $0.0174 \mu \mathrm{g} / \mathrm{m} 3$. Berdasarkan hasil analisis uji $\mathrm{t}$, diperoleh $\mathrm{t}$ hitung $=-5.93,(\mathrm{df})=16$, pada $\alpha=0.05 \mathrm{t}$ tabel $=2.120$. Sehingga dapat dinyatakan bahwa pembakaran briket batubara dengan nyata dapat meningkatkan kadar BaP di udara ambien.

\section{Perhitungan Recovery BaP}

Recovery merupakan nilai perolehan kembali zat yang sudah diperlakukan sama dengan contoh uji. Hal ini berguna untuk mengetahui apakah zat yang diuji mengalami kerusakan atau tidak selama diperlakukan. Semakin tinggi prosentase perolehan kembali maka prosedur tersebut semakin baik, dan berarti zat yang diuji tidak mengalami kerusakan, rumus $\%$ Recovery sebagai berikut:

$$
\% \mathrm{R}=\frac{\mathrm{X} \text { spike }-\mathrm{X} \text { contoh uji }}{\mathrm{X} \text { target }} \times 100
$$

Keterangan:

$\% \mathrm{R} \quad=$ Persen Recovery

$\mathrm{X}$ spike $\quad=$ Nilai konsentrasi contoh uji yang ditambahkan standar

$\mathrm{X}$ contoh uji $=$ Nilai konsentrasi contoh uji

$\mathrm{X}$ target $\quad=$ Konsentrasi standar yang ditambahkan pada contoh uji

Recovery $\mathrm{BaP}$ hasil penelitian adalah $86 \%$, 107\%, 95.4\% dengan rerata 96.3\%. Nilai recovery disajikan pada Tabel 3.

\section{Kondisi Udara Saat Penelitian}

Dari hasil pengukuran arah dan kecepatan angin maka dapat disimpulkan bahwa kondisi udara tidak mempengaruhi pengambilan contoh uji saat penelitian. Hal ini dapat dilihat dari wind rose dan persentase kecepatan angin pada Gambar 3. dan 4.

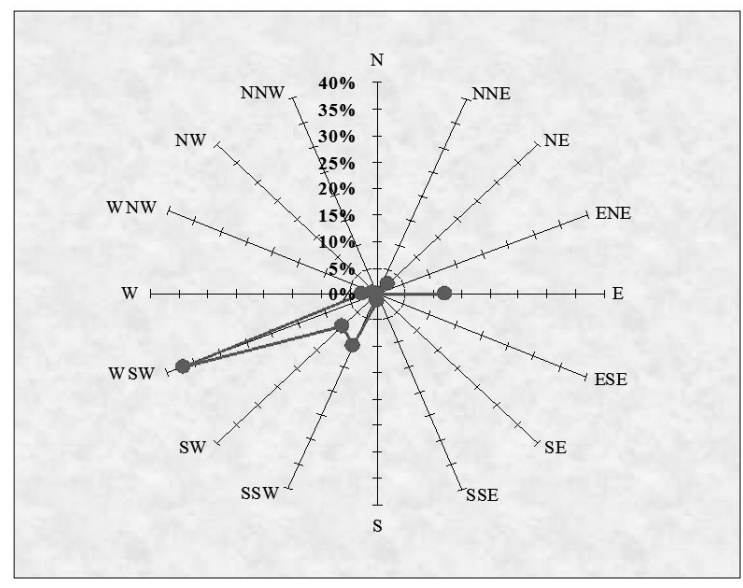

Gambar 3. Windrose Kondisi Udara

Tabel 3. Recovery Benzo(a)pyrene

\begin{tabular}{cccccc}
\hline Ulangan & $\begin{array}{c}\text { Konsentrasi } \\
\text { Contoh uji }\end{array}$ & $\begin{array}{c}\text { Standar yang } \\
\text { ditambahkan }\end{array}$ & $\begin{array}{c}\text { Konsentrasi } \\
\text { yang } \\
\text { ditemukan } \\
\text { kembali } \\
(\mathrm{ng} / \mathrm{g})\end{array}$ & Recovery & $\begin{array}{c}\text { Rata-rata } \\
\text { Recovery }\end{array}$ \\
\hline I & 2669 & 4784 & 6803 & $(\%)$ & $(\%)$ \\
II & 2534 & 8152 & 11331 & 107 & 96.3 \\
III & 3041 & 8152 & 10820 & 95.4 & \\
\hline
\end{tabular}




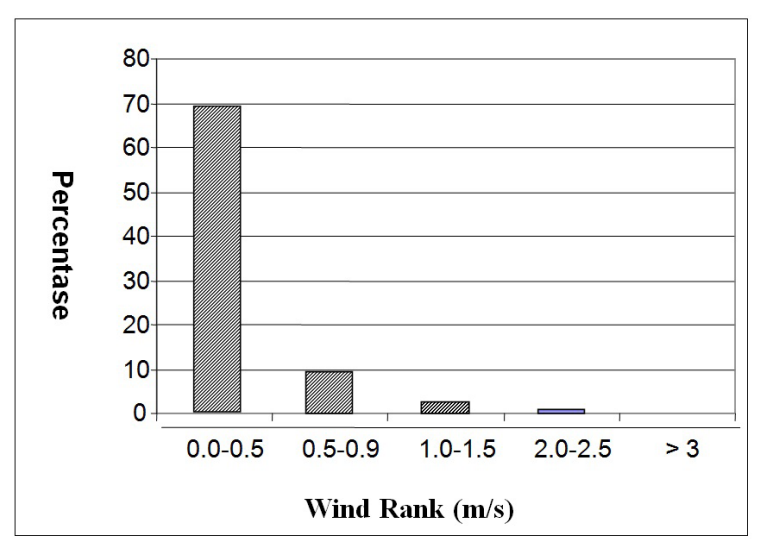

Gambar 4. Persentasi Kecepatan Angin

\section{KESIMPULAN}

Pembakaran briket batubara dapat meningkatkan kadar benzo(a)pyrene di udara ambien. Hasil penelitian menunjukkan adanya perbedaan nyata rata-rata konsentrasi $\mathrm{BaP}$ sebelum pembakaran briket batubara yaitu dengan nilai $(0.002 \mu \mathrm{g} / \mathrm{m} 3)$ dan konsentrasi rata-rata $\mathrm{BaP}$ di udara ambien setelah adanya kegiatan pembakaran briket batubara adalah $(0.0174 \mu \mathrm{g} / \mathrm{m} 3)$.

Jika dibandingkan dengan Baku mutu BaP di negara lain seperti Italy dan Belanda batas konsentrasi $\mathrm{BaP}$ di udara ambien yaitu $0.001 \mu \mathrm{g} / \mathrm{m} 3$. Maka konsentrasi BaP hasil penelitian ini jauh lebih tinggi dibandingkan dengan baku mutu Negara tersebut.

Hasil ini diharapkan dapat digunakan sebagai referensi berbasis ilmiah dalam merumuskan, mengambil tindakan dan kebijakan yang tepat dan terarah untuk mengatasi permasalahan lingkungan.

\section{DAFTAR PUSTAKA}

1) K. Kawata, H. Mukai, H. Taneoka, H. Tanabe and A. Yasuhara, 1997, Variations of Carcinogenic Polycyclic Aromatic Hydrocarbons In Airborne Particulate Matter In Niigata, Japan, Toxicological and Environmental Chemistry, Vol.60, pp27-37

2) Warouw, S. P., 2006, Analisis Risiko Kesehatan Pemanjanan Benzo(a) Pyrene Pada Petugas Pintu Tol di Jabotabek, Jakarta, Universitas Indonesia.

3) Yan, J.H., You, X.F., Li, X.D., Ni, M.J., Yin, X.F., Cen, K.F., 2004, Performance of PAHs Emission from bituminous coal combustion, Journal of Zhejiang University Science, ISSN 1009-3095, 5 (12) : 1554-1564

4) Chun,T.L., Huan, K.Z., Lien,T.H., Wen, J.L., and Meng, C.T., 2001, PAH Emission From The Incineration Of Three Plastic Waste, Environment International, V.27.i.1, Jul01

5) Iriani, D.U., 2004, Hubungan Antara Kualitas Udara Ambien, ISPU dengan Kejadian Asthma/Bronkitis di DKI Jakarta Tahun 2002-2003., Jakarta, Universitas Indonesia.

6) M.N. Kayali., S. Ruboi-Barroso., and L.M. Polo-Diez., 1995, Rapid PAH Determination in Urban Particulate Air Samples by HPLC with Fluorometric Detection and Programmed Excitation and Emission Wavelength Pairs, Journal Chromatographic Science, Vol.33., pp 181-184 